\title{
Identification of Elk-vehicle incident hotspots on state route 20 in Washington State
}

\author{
Jennifer Sevigny $\mathbb{D} \cdot$ A Amanda Summers • \\ Glen Kalisz $\cdot$ Kelly McAllister
}

Received: 27 July 2020 / Accepted: 20 March 2021 / Published online: 4 April 2021

(C) The Author(s) 2021

\begin{abstract}
Context Identifying risk zones for wildlife-vehicle incidents is essential for creating effective mitigation efforts on major road networks. Wildlife-vehicle collision data are often used to identify hotspot areas without consideration of species spatial distributions. Objectives Evaluating both can reveal spatiotemporal patterns that can improve mitigation success.

Methods We summarized elk-vehicle incident (EVI) data on State Route 20 (SR 20) in Washington State between 2012 and 2019. We also collared 23 elk residing in the vicinity of SR 20 and used GPS location data to identify home ranges and road crossings. We compared EVI and elk road crossing data to identify hotspot locations on SR 20 to help inform mitigation.

Results Our EVI and elk crossing data had a nonrandom distribution along a $38 \mathrm{~km}$ section of SR 20 associated with the $95 \%$ home ranges of 8 female elk sub-herds. We found EVI data alone were an effective indicator of elk spatial distribution and movement in relation to collision hotspots along SR 20. Our results
\end{abstract}

J. Sevigny $(\bowtie) \cdot$ A. Summers

Stillaguamish Tribe of Indians, Natural Resources

Department, P.O. Box 277, Arlington, WA 98223, USA

e-mail: jsevigny@stillaguamish.com

G. Kalisz $\cdot$ K. McAllister

Washington State Department of Transportation, Fish and Wildlife Program, 310 Maple Park SE, Olympia,

WA 98504, USA also indicated a strong association between elk crossings and EVIs by milepost. While the spatial distribution of elk sub-herds was a good predictor of EVI risk zones, EVI frequency was not associated with an increase in elk population.

Conclusions Classifying EVI and road crossing distributions as high risk zones is the first step preceding mitigation and protection measures to prevent elkvehicle collisions. Specific identification of hotspots will result in more effective and successful installations of high cost mitigation efforts such as wildlife crossing structures.

Keywords Elk road crossing $\cdot$ Habitat connectivity $\cdot$ Collision hotspot $\cdot$ Home range $\cdot$ Roadkillmitigation $\cdot$ Spatiotemporal distribution

\section{Introduction}

Road networks can negatively impact wildlife by creating barriers to habitat connectivity and causing mortality and habitat loss that could affect population viability (Trombulak and Frissell 2000; Forman et al. 2003; Baguette and Van Dyke 2007). Brady and Richardson (2017) state that roads are the largest human artifact on the planet, covering approximately $20 \%$ of the U.S. landscape. How species adapt to road networks can have a considerable impact on population persistence and sustainability. Movement is key to survival for large mammals, such as elk (Cervus 
elaphus), and roads can decrease survivorship and cause behavioral shifts that are costly to individuals and populations (Fahrig and Rytwinski 2009; Prokopenko et al. 2017). Major road networks that bisect home ranges and migration corridors can be detrimental to elk herds and can alter habitat selection and movement patterns on the landscape (Biggs et al. 2004; Dodd et al. 2007; Gagnon et al. 2007).

In addition to impacts on wildlife populations, managers must consider the human safety aspect associated with road networks that intersect home range and corridor habitats. Elk-vehicle incidents (EVI, collision reports and carcass removals) can lead to human injury or death as well as economic costs associated with vehicle damage, human injury, accident investigation, and carcass removal (Conover et al. 1995; Myers et al. 2008; Huijser et al. 2009). Elk-vehicle incidents can also lower social tolerance for elk in developed areas and increase public pressure to reduce elk populations. The North Cascades elk herd (NCEH) is experiencing a relatively high incidence of collisions with vehicles in the Skagit Valley area along State Route 20 (SR 20) in Washington State.

The NCEH is a native herd that was harvested to near extinction in the early 1900s and is now recovering following multiple augmentation efforts (Murie 1951; WDFW 2015). As the NCEH population increases, managers are challenged with promoting herd growth and addressing human-elk conflicts. Continued growth and expansion of the NCEH could result in greater numbers of elk along major road systems creating the need for mitigation strategies in response to EVIs.

A recent study on the NCEH found that female elk sub-herds were relatively sedentary and did not display seasonal migratory behavior (Sevigny et al. 2018). This was true for female sub-herds in upland managed forests and in lowland agricultural areas along SR 20. The SR 20 corridor includes a $37 \mathrm{~km}$ reach that falls within Elk Area 4941, which is designated as a special hunt area because it is considered a human-elk conflict zone due to elk presence on agricultural properties. Collared female elk within this area maintained small, discrete year-round home ranges with consistent boundaries regardless of deliberate human disturbance (Sevigny et al. 2018). There was little spatial overlap between sub-herds and collared elk spent $\geq 50 \%$ of their time in areas $\leq 11 \%$ of their overall home range areas. Elk sub-herds also displayed a high level of site fidelity, which could lead to persistent use of established travel corridors and road crossing locations (Bruggeman et al. 2007; Bunnefeld et al. 2011; Neumann et al. 2012).

Successful management strategies within conflict areas must address EVI hotspot locations and spatiotemporal patterns in elk crossing activity along major road networks. While many studies have focused on the identification of wildlife-vehicle hotspots on road systems (Ramp et al. 2005; Morelle et al. 2013; Garrah et al. 2015), few have investigated elk crossing patterns in relation to major road networks (Dodd et. al. 2007, Gagnon et al. 2007), geographic distribution, and temporal patterns (Dodd et al. 2006). An EVI occurs when an elk and a vehicle coincide in space and time and understanding the probability of these events is essential for mitigation planning. Elk-vehicle incident probabilities depend on the space use patterns of both elk and traffic, landscape characteristics, elk and driver behavior, and various seasonal influences (Johnson et al. 2002; Morelle et al. 2013).

Often EVI datasets are incomplete because many are not reported so we combined EVI data with elk distribution data to evaluate how each dataset contributes to the identification of high collision risk zones (Dyer et al. 2002; Waller and Servheen 2005; Dodd et al. 2007). Our primary objective was to use EVI data to identify collision hotspot areas on SR 20 and compare hotspots with elk locational data to assess whether EVI data alone can determine high risk areas for mitigation. We also looked at spatiotemporal patterns in both EVI and elk crossing data.

\section{Study area}

We conducted this study in northwest Washington State on the west side of the North Cascades Range in northern Skagit County (Fig. 1). The study area encompassed approximately $400 \mathrm{~km}^{2}$, and was located within Game Management Units (GMUs) 418 and 437 (including Elk Area 4941). Elk Area 4941 occurred within GMU 437 and was designated a special hunt area by the Washington Department of Fish and Wildlife (WDFW) with elk harvest occurring between July 1 and March 31. Multiple elk sub-herds resided in this area year-round and traffic rates varied 
Fig. 1 Location of study area on State Route 20 within Game Management Units (GMU) 418 and 437 (including Elk Area 4941) in northwest Washington State, USA

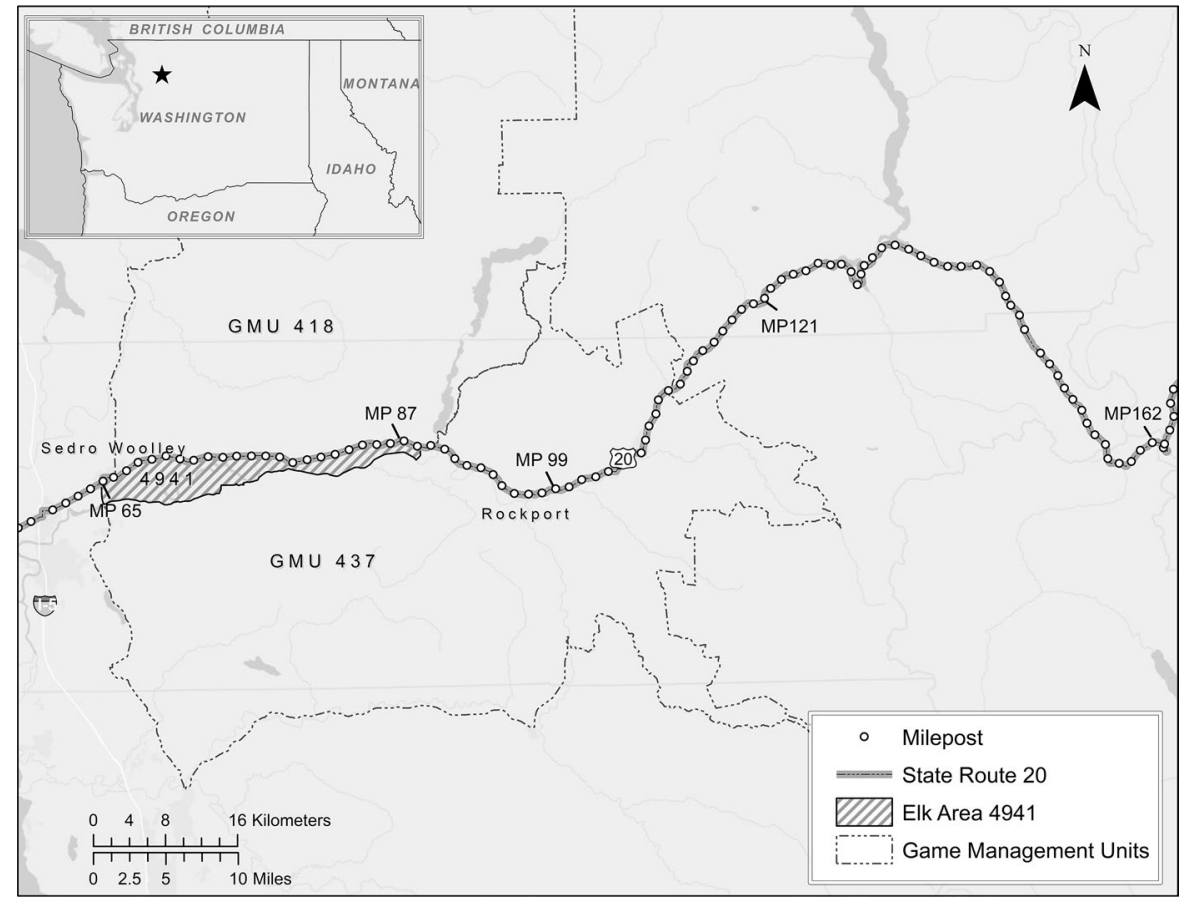

with higher volumes during morning and evening commute hours and summer months when there was open access to Washington Pass. The valley bottom included mostly private residential and agricultural lands with some state, federal, and private forestlands interspersed throughout the region. Land cover consisted primarily of agricultural crops, riparian forest, and rural residential development. Agricultural uses included hay, food crops, and livestock. The industrial forest lands were primarily private ownerships with some state forest parcels. These were dominated by Douglas fir (Pseudotsuga menziesii) and western hemlock (Tsuga heterophylla) with western red cedar (Thuja plicata), alder (Alnus rubra) and maple (Acer spp.) also occurring throughout the upland regions. Upland topography was rolling foothills with elevations ranging from 100 to $750 \mathrm{~m}$. The climate was maritime (Franklin and Dyrness 1988) with annual precipitation ranging from 120 to $300 \mathrm{~cm}$ and annual temperatures from $-4{ }^{\circ} \mathrm{C}$ to $27^{\circ} \mathrm{C}$ (U.S. Climate Data https://www.usclimatedata.com/climate/mount-vernon/washington/united-states/uswa0288).

\section{Methods}

EVI data

Our EVI data analysis focused on the SR 20 corridor between Interstate 5 and Washington Pass (mileposts 59.5-162.50). We obtained EVI data from January 1, 2012-December 31, 2019 for the entirety of Washington State highways, including SR 20 in the Skagit Valley west of Washington Pass. We assembled EVI data from three sources, carcass removal reports, salvage reports, and collision reports and removed duplicate records to avoid representing the same incident with multiple data sources. Elk carcass removal records were generated when a Washington State Department of Transportation (WSDOT) employee removed an elk carcass from the highway and documented its location using either a paper form (pre-2015) or an iPad (post-2015). Carcass removal records accounted for the majority of our EVI data and were managed by WSDOT and evaluated using 
a rigorous vetting process. Every carcass removal record was verified for species and spatial accuracy and questionable records were rectified by contacting the WSDOT staff member who originally reported the event. Elk salvage records were generated when a citizen took possession of an elk killed by a vehicle and submitted the details to the WDFW. Citizens were required by the Washington State Salvage Law (WAC 220400 40), enacted July 1, 2016, to obtain a free online permit through the WDFW when salvaging an elk. The WDFW provided raw salvage data to WSDOT where it was subjected to the same rigorous vetting process as the carcass removal data, and then merged with WSDOT's Carcass Removal Database. We therefore considered elk salvage reports as carcass removal reports because both were managed and vetted by WSDOT. Collision data were generated from officer-submitted collision reports (primarily Washington State Patrol) created when an officer responded to a collision. Elk-vehicle collisions were a subset of WSDOT's statewide collision database.

We used Kernel Density Estimation Plus (KDE+) to identify statistically significant clusters of EVIs (Bíl et al. 2015; Bartonička et al. 2018; Favilli et al 2018) using the total EVI dataset on SR 20. Clusters were associated with strength and therefore were ranked by significance. To determine the relative risk of a road segment, we combined our $\mathrm{KDE}$ + clusters with conventional KDE Utilization Distributions (UDs, Seaman and Powell 1996; Danks and Porter 2010; Kociolek et al. 2016; Favilli et al. 2018) and EVI frequencies by milepost to verify EVI hotspots. Hotspot areas were identified based on the presence of significant EVI clusters, greater than average EVI frequencies, and higher KDEs. We evaluated EVI frequency distributions and KDEs on an annual basis to determine if hotspot locations were consistent over time. We then compared the EVI hotspots with road crossings generated from elk locational data in the study area. We also calculated the correlation coefficient between annual elk population estimates (WDFW Status and Trends Reports 2012-2019) and EVI annual totals in Excel 2016.

\section{Elk location data}

We targeted female elk groups for capture on the valley bottom and in the urban-wildland interface north and south of the SR 20 corridor. We applied GPS collars to 21 female elk ( $\geq 1$ year old) and 2 male elk ( 1 year old) in targeted sub-herds throughout the study area using modified $1.2 \mathrm{~m}$ wide $\times 1.8 \mathrm{~m}$ high $\times 2.4 \mathrm{~m}$ long collapsible (Roper et al. 1971; McCullough 1975; Thompson et al. 1989) clover traps (Clover 1954) baited with apples and mineral licks. We did not collar adult male elk due to low survivorship associated with harvest. We selected our trap sites at known elk use areas across the landscape using local knowledge and past elk observations.

We captured elk following animal handling guidelines described in Sikes et al. (2016) between November 1 and March 31 for each capture year. All trap sites were monitored with cameras and Vectronic trap transmitters were used to monitor trap activity. We placed traps on public and private lands based on elk use and landowner support. We used Vectronic GPS Plus and Vertex Lite-4D collars programmed to take multiple fixes each day (fix intervals ranged from 5 to $115 \mathrm{~min}$ ) with data uploaded via the Iridium or Globalstar satellite systems. The WSDOT provided three Iridium collars outfitted with a user-defined virtual fence and proximity sensors. The virtual fence option allowed us to collect more GPS points depending on the location of the animal in relation to SR 20. These collars were used on four elk between 2014 and 2017 with a default sampling interval of $1 \mathrm{~h} 55 \mathrm{~min}$ that was reduced to 50 min once an elk was within $200 \mathrm{~m}$ of SR 20 . Unlike the virtual fence, the proximity sensing electronics monitored a VHF frequency for pulses from proximity transmitters that were deployed along the highway at select locations. If a proximity transmitter was detected, GPS fix interval was dropped to $5 \mathrm{~min}$.

We collected elk locational data from 2013 to 2019 and assumed locations from one or more collared animals were representative of the entire subherd given the aggregated structure of female elk (Craighead et al. 1973; Van Dyke 2007). The two yearling male elk were assumed to be representative of their associated female sub-herd. Elk were monitored daily for capture myopathy for four weeks following capture (Beringer et al. 1996) with no capture myopathy mortalities detected for captured elk. During the study period, 3 collared adult female elk were killed by vehicles on SR 20. 
Data analysis

We imported our data into Excel 2016 for sorting and removal of latitude and longitude values of zero for each animal. We analyzed a total of 137,417 fixes $(\bar{x}=5,975, \mathrm{SD}=761)$ for all elk combined. We assigned collared elk to 8 known sub-herds (Sevigny et al. 2018) in order to pool road crossings by subherd. Number of collars per sub-herd ranged from 1 to 7 and some collars within groups had overlapping periods between 2013 and 2019. For a comparison between EVI hotspot locations and elk sub-herd spatial distributions along the SR 20 corridor study area, home range (HR) and core areas were calculated for individuals and sub-herds respectively and data were pooled across years (2013-2019) for all analyses.

We estimated HR using the Kernel Density Estimation (KDE) tool of the Spatial Analyst Tool Extension in ArcMap 10.5.1 at the 95\% exceedance value (Seaman and Powell 1996; Kernohan et al. 2001; Powell and Mitchell 2012). We also estimated core use areas at a $50 \%$ isopleth to identify the most frequently used spaces within each HR. We estimated HR and core areas for the entire period of record for each female elk group, as represented by the combined collared animals in each group. In Arc 10.5.1, we calculated the search radius (bandwidth $h$ ) based on spatial configuration and the number of input points using the Solve-the-Equation (STE) method (Wand and Jones 1994; Jones et al. 1996). This approach corrected for spatial outliers and was most appropriate given the size of our dataset (Silverman 1986; Hemson et al. 2005).

For each collared individual, we assigned a value of 1 for consecutive fix locations that intersected SR 20 to indicate a crossing or a 0 if track lines did not intersect the highway (Danks and Porter 2010; Neumann et al. 2012). Of our 23 collared elk, 22 (20 females, 2 yearling males) exhibited crossings on SR 20 . We then sorted crossings for individuals and subherds by year, month, and time block and compared location data to EVI data. Because we did not have GPS collars on the landscape in 2012, comparisons of EVIs to road crossings for hotspot identification were made between 2013 and 2019. Given our maximum fix interval of $115 \mathrm{~min}$, we used time bins of two hour intervals to group crossings and elk-vehicle collisions based on the 24-h time clock. We were interested in identifying whether more EVIs andcrossings occurred during periods of low light (crepuscular/ night) compared to daylight hours. We summarized crossings by milepost by counting the lines between consecutive fixes that intersected SR 20 for each mile segment.

\section{Results}

From 2012 to 2019, we obtained 2,527 EVI records for Washington State and found a total of 2,457 associated with the 10 elk herd ranges occurring within the state (Fig. 2). Within the NCEH range, a total of 248 EVIs occurred, which accounted for $10 \%$ of statewide totals. Of the 248, 229 EVIs (92\%) occurred along SR 20, west of Washington Pass within a $37 \mathrm{~km}$ (23 mile) reach between mileposts 66 and 89 . The 229 EVI records identified on SR 20 were comprised of 55 elk-vehicle collision records and 174 carcass removal records. We found relative frequencies of $42 \%$ female, $21 \%$ male, and $37 \%$ unknown in our EVI data during the project period. Age classes were largely unknown with relative frequencies of $53 \%$ unknown, $29 \%$ adult, and $17 \%$ juvenile.

Compared to statewide totals, EVIs on SR 20 show a similar pattern in terms of elk killed on a monthly basis (Fig. 3). The EVI annual average for SR 20 was $29.5(\mathrm{SD}=12.9)$ and the average EVI rate/mile/year was $1.2(\mathrm{SD}=0.6)$. We compared annual EVI totals to annual population estimates for the NCEH and found greatest EVIs occurred in 2012 and 2013 when elk population estimates were lower than current estimates (Fig. 4). We found a weak negative correlation between EVI totals and elk population estimates ( $r=$ $0.3)$.

Using KDE+, we analyzed the 229 EVIs between 2012 and 2019 and detected 29 total clusters with 26 clusters occurring within the hotspot areas. From these clusters, we identified 4 EVI hotspots on SR 20 between mileposts 65 and 89 using 95\% KDE, $\mathrm{KDE}+($ cluster strength) and EVI frequencies collectively (Fig. 5). Within the $38 \mathrm{~km}$ reach of SR 20 where the EVIs occurred, the identified hotspots covered a total of $24 \mathrm{~km}$ (15 miles) of SR 20 and accounted for 215 (93\%) of the total records between 2012 and 2019. Hotspots were identified as 1: MP 67-70 (8 clusters, EVI=47), 2: MP 75-78 (6 clusters, EVI=69), 3: MP 79-82 (7 clusters, EVI=71), and 4: MP 84-86 (5 clusters, EVI=24). We used our 
Fig. 2 Elk-vehicle Incident (EVI) totals by elk herd (70 records were not associated with a specific herd) in Washington State, USA (2012-2019)

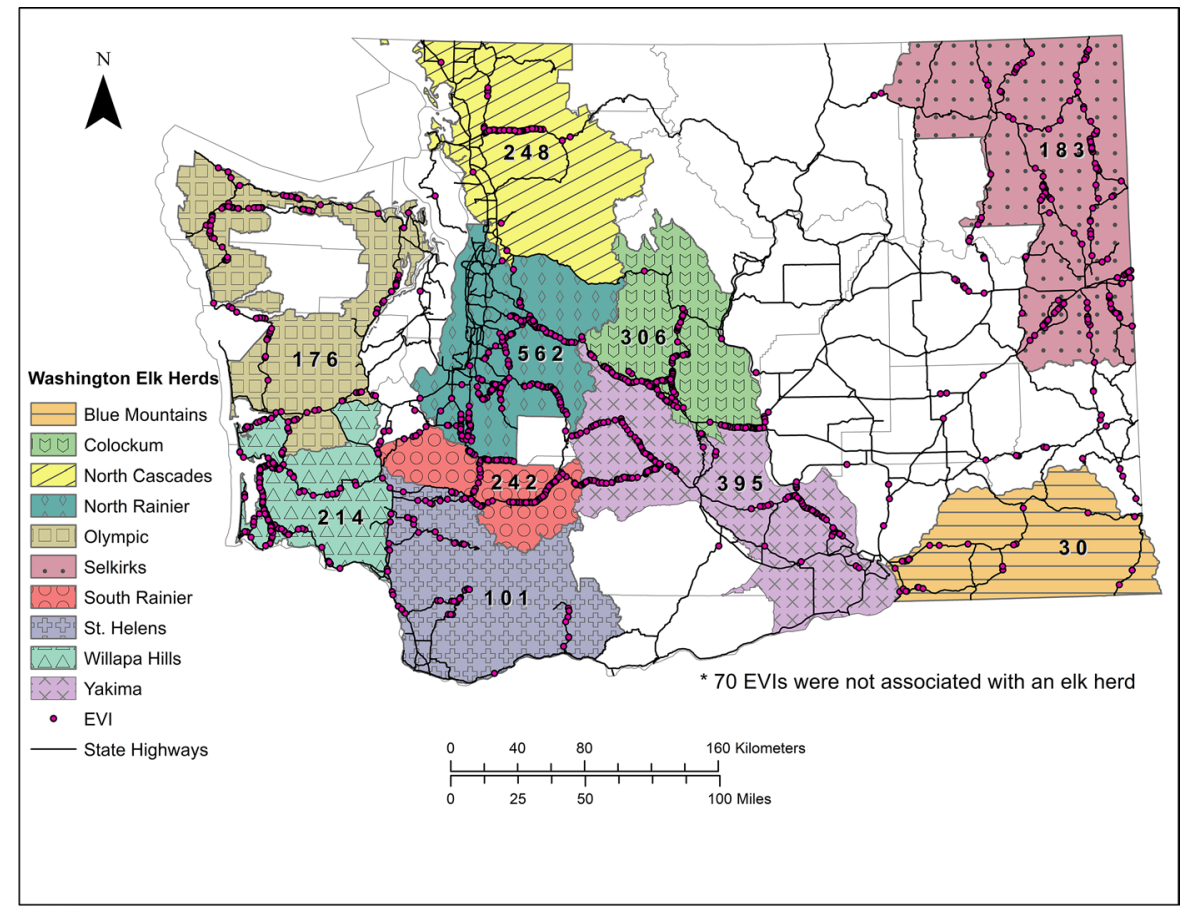

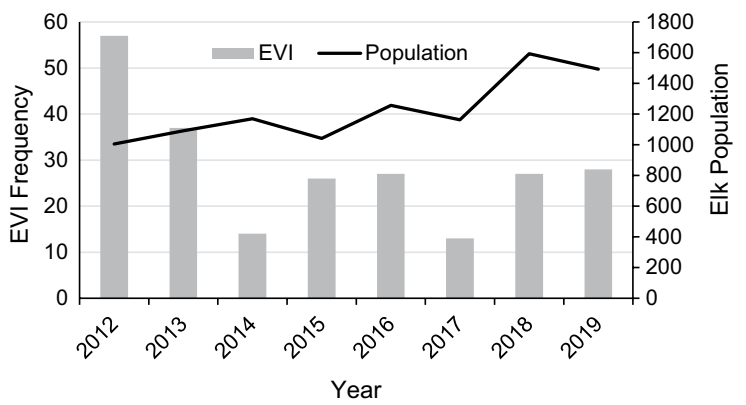

Fig. 4 Annual Elk-vehicle Incident (EVI) totals on State Route 20 compared to North Cascade elk herd population estimates in Washington State, USA (2012-2019; WDFW Status and Trends Reports)

sub-herds were relatively sedentary, displayed strong site fidelity, and showed little to no spatiotemporal overlap in 95\% HR areas. Female sub-herd hotspot associations and range areas are described in Table 1.

Home range areas $(95 \%)$ ranged from $1.55 \mathrm{~km}^{2}$ to $32.37 \mathrm{~km}^{2}$ and core areas (50\%) ranged from 0.05 $\mathrm{km}^{2}$ to $2.27 \mathrm{~km}^{2}$. Our elk locational data indicated that all sub-herds, except sub-herd 6, had road crossings on SR 20 associated with their fix locations. Collared elk in sub-herds 3 and 8 had the largest HR 
Fig. 5 Elk-vehicle Incident (EVI) hotspots derived using 95\% KDE (EVI density), KDE + (ranked by cluster strength) and EVI frequency (including line average) by milepost for State Route 20 (2012-2019) in Washington State, USA

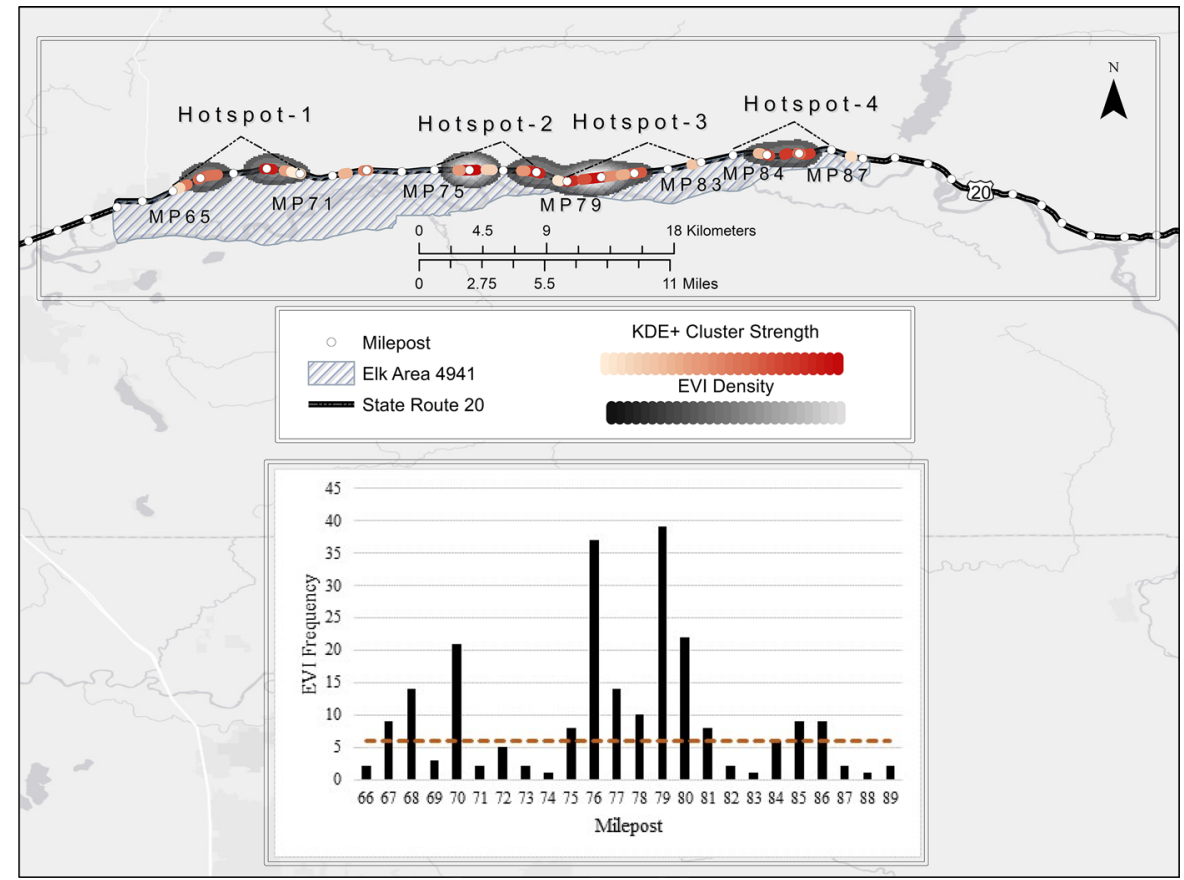

Fig. 6 Elk sub-herd 95\% home range and $50 \%$ core areas associated with elk-vehicle incident hotspots on State Route 20 in Washington State, USA (2012-2019)



and core areas. Core use (50\%) areas for 5 sub-herds between mileposts 75 and 101.5 were $<1 \mathrm{~km}$ from SR 20. We found that $74 \%$ of recorded EVIs occurred within the $95 \%$ HRs of these 5 sub-herds. Sub-herds
7 and 8 had the longest road segments associated with their 95\% HRs, $11.02 \mathrm{~km}$ and $7.66 \mathrm{~km}$ respectively. However, we found that only $13 \%$ of EVIs occurred within these road segments. 
Table 1 Elk sub-herds with associated road segments, elk-vehicle incident (EVI) hotspots, home range (95\%) areas, core $(50 \%)$ areas, and core use area distances from State Route 20 (SR 20) in Washington State, USA (2013-2019) Sub-herd

\begin{tabular}{lllllll}
\hline $\begin{array}{l}\text { Associated } \\
\text { milepost seg- } \\
\text { ments }\end{array}$ & $\begin{array}{l}\text { Road seg- } \\
\text { ment length } \\
(\mathrm{km})\end{array}$ & $\begin{array}{l}\text { Associated } \\
\text { EVI hotspot } \\
\#\end{array}$ & $\begin{array}{l}\text { 95\% } \\
\text { HR area } \\
(\mathrm{km} 2)\end{array}$ & $\begin{array}{l}\text { 50\% Core } \\
\text { area }\left(\mathrm{km}^{2}\right)\end{array}$ & $\begin{array}{l}\text { Distance from 50\% } \\
\text { cores to SR 20 (km) }\end{array}$ \\
\hline 1 & $67-71.5$ & 5.20 & 1 & 8.46 & 0.14 & 2.72 \\
2 & $74-74.5$ & 2.25 & -- & 8.26 & 0.44 & 2.25 \\
3 & $75-78$ & 4.83 & 2 & 32.37 & 0.79 & 0.37 \\
4 & $76-78$ & 3.22 & 2 & 4.26 & 0.09 & 2.62 \\
5 & $78.5-80.5$ & 3.62 & 3 & 1.55 & 0.05 & 0.05 \\
6 & $80.5-82.5$ & 3.01 & 3 & 1.90 & 0.07 & 0.21 \\
7 & $83.5-91$ & 11.02 & 4 & 7.66 & 0.44 & 0.19 \\
8 & $96-101.5$ & 7.66 & -- & 15.72 & 0.93 & 0.42 \\
\hline
\end{tabular}

Elk crossings occurred between mileposts 67.5 and 99 on SR 20 with a total of 774 crossings from 22 of our 23 collared elk $(\bar{x}=33.7$, $\mathrm{SD}=41.4)$. Locational data associated with crossings accounted for $2 \%$ of the total data analyzed for all elk. We obtained an average of 720.4 $(\mathrm{SD}=225.2)$ locations per elk $\leq 200 \mathrm{~m}$ from $\mathrm{SR}$ 20 , which accounted for $12 \%$ of overall data. Total road crossings per sub-herd ranged from 0 to 382 $(\bar{x}=96.8, \mathrm{SD}=119.6)$. Our collared elk had an annual average of 110.6 crossings $(S D=64.7)$ from 2013 to 2019 . Monthly crossing frequencies varied with the lowest number crossings occurring in June and October. For crossings with fix intervals $<2 \mathrm{~h}$, $91 \%$ occurred during night and crepuscular time periods. Similarly, $99 \%$ of elk-vehicle collisions occurred during those time periods (Fig. 7).

The majority of crossings (99\%) were from collared elk in sub-herds $1,3,4,5$, and 7 and were associated with hotspots 1-4 (Table 2). The other 3 sub-herds had crossing totals ranging from 0 to 6. Hotspot 3 had $50 \%$ of the total crossings and $31 \%$ of total EVIs during our study period and fell within the $95 \% \mathrm{HR}$ of sub-herd 5 . We found that 73 crossings (9.4\%) occurred outside of the $95 \%$ EVI KDEs. Of the 73, 57 of those crossings were west of Hotspot 4 at the eastern end of Elk Area 4941 (Fig. 8). Between 2013 and 2019, the number of elk crossings by milepost ranged from 1 to $315(\bar{x}=45.4, \mathrm{SD}=71.3)$ within the study area and we found a strong association between crossings and EVIs by milepost $(r=0.80)$ as well as between crossings and EVIs by hotspot $(r=0.80$; Fig. 9$)$. (a)

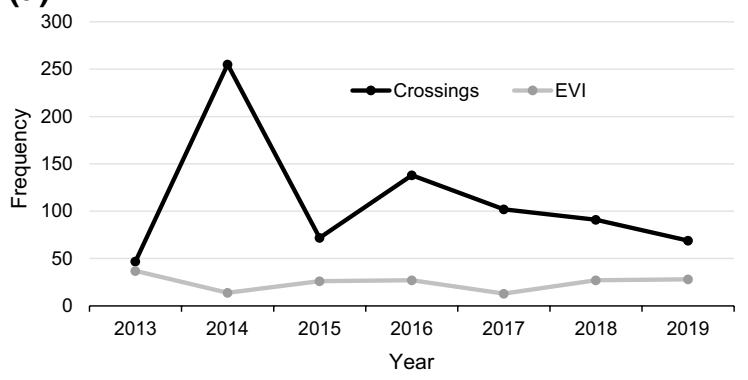

(b)

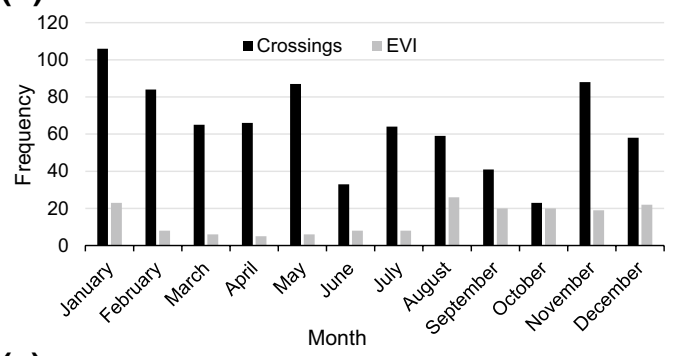

(c)

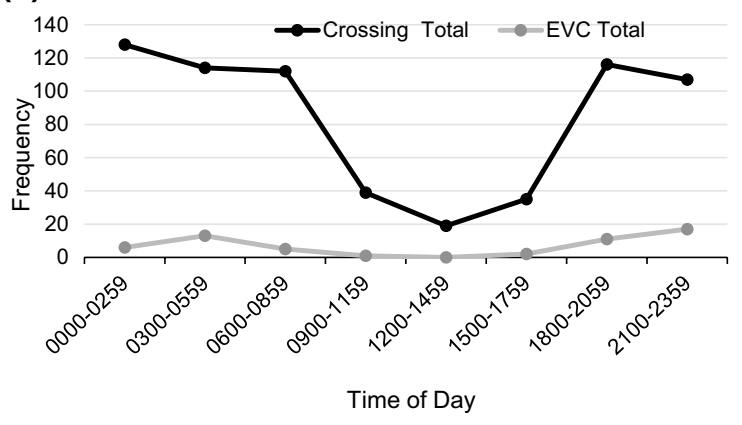

Fig. 7 Comparison of road crossing and elk-vehicle incident (EVI) frequencies by year (a), month (b), and road crossing and elk-vehicle collision data by 24-h time bin (c) for State Route 20 in Washington State, USA (2013-2019) 
Table 2 Crossing totals by elk sub-herd with milepost ranges, road segment lengths, and associated elk-vehicle incident (EVI) hotspots on State Route 20 in Washington State, USA (2013-2019) Sub-herd

\begin{tabular}{lrlll}
\hline & Crossing total & Crossing milepost ranges & $\begin{array}{l}\text { Crossing road seg- } \\
\text { ment length }(\mathrm{km})\end{array}$ & $\begin{array}{l}\text { Associated } \\
\text { EVI hotspot } \\
\text { \# }\end{array}$ \\
\hline 1 & 40 & $67.5-68.5 ; 69.5-70.5$ & 3.22 & 1 \\
2 & 6 & $73-73.5$ & 0.80 & - \\
3 & 100 & $76-76.5 ; 77.5-78$ & 1.61 & 2 \\
4 & 90 & $75.5-76.5 ; 77.5-78$ & 2.41 & 2 \\
5 & 382 & $79-81.5$ & 4.02 & 3 \\
6 & 0 & - & - & 4 \\
7 & 154 & $82.5-88$ & 8.85 & - \\
8 & 2 & $99-99.5$ & 0.80 & 3 \\
\hline
\end{tabular}

Fig. 8 Elk crossings associated with elk-vehicle incident (EVI) hotspots (based on $95 \% \mathrm{KDE}$ ) on State Route 20 in Washington State, USA (2013-2019)

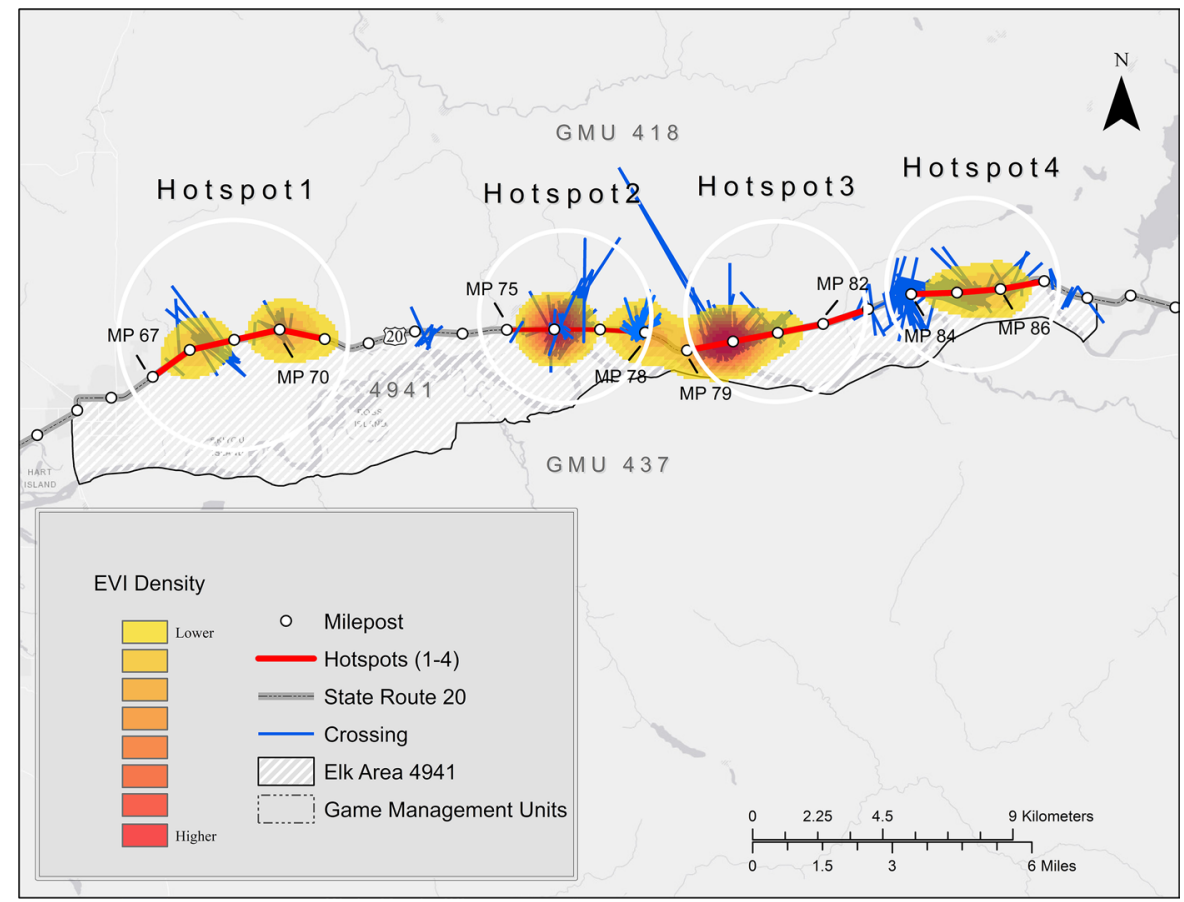

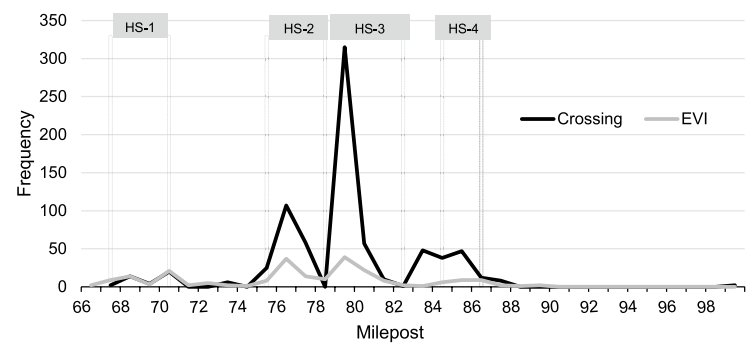

Fig. 9 Frequency of elk road crossing and elk-vehicle incidents (EVI) by milepost and hotspot (HS) on State Route 20 in Washington State, USA (2013-2019)

\section{Discussion}

This study showed that EVI data were an effective indicator of elk-vehicle collision hotspots and elk crossing activity on SR 20 . We found that $9 \%$ of statewide EVI totals between 2012 and 2019 occurred along a $38 \mathrm{~km}$ reach of SR 20. This portion of the highway falls within Elk Area 4941 and the HRs of at least 6 female elk sub-herds. With 93\% of the EVIs associated with the NCEH occurring in a relatively small reach of SR 20, it is likely that hotspots are 
related to sub-herd HRs in this region. Considering range areas along with EVI data will make mitigation measures more effective. Both EVI and crossing data were clustered on SR 20 and annual totals had similar spatial distributions throughout our study period.

Annual totals indicated the highest numbers of EVIs occurred in 2012 and 2013 when elk population estimates were at their lowest levels for the study period. Given the decrease in the elk population estimate for 2015, it is possible the relatively aggressive conflict-related harvest that occurred in the 2012-2013 season caused an increase in elk road crossings and consequently EVIs. Our crossing data do not reflect this in 2013, however we had no GPS collars on the landscape in 2012. We suspect there may be a link between elk crossings and hunting/hazing activities, but this is difficult to quantify given the length of the conflict harvest season and the effects of other biologically significant seasons such as rutting and calving. Elk Area 4941 was created to address human-elk conflicts in the Skagit Valley and antlerless elk are often the target of this hunt. We found that $99 \%$ of EVIs and $99 \%$ of crossings occurred on SR 20 within the 4941 boundary. The majority of our GPS collars were applied in 4941, which could explain the crossing frequency in this area. However, elk collared outside of the 4941 boundary crossed SR 20 less frequently.

We found EVI totals on SR 20 peaked during the months of August and September from 2012 to 2019 , which is contrary to other summarized elkvehicle collision data for western Washington where peak months were January and February (Myers et al. 2008). Gunson and Clevenger (2003) attributed increases in elk-vehicle collisions in the fall to calf recruitment and an overall increase in elk numbers. Other studies involving ungulate-vehicle collisions suggest an increase in collisions in late summer and fall due to the breeding season, migration, and onset of hunting seasons (Puglisi et al. 1974; Romin and Bissonette 1996; Huijser et al. 2008). In our case, the EVI peak months could be associated with calf recruitment, breeding season and the onset of harvest seasons.

Temporal patterns for road crossings differed from EVIs in terms of monthly distributions. We found fewer crossings occurred in June and October, possibly related to calving and rutting activities. We did not collar adult males so crossing patterns associated with adult male elk are unknown along the SR 20 corridor. Male elk may be using the landscape differently so there are unknowns associated with mature bull movement and landscape use. Similar to EVI results, we found that the distribution of crossings corresponded with hours of darkness. Both EVI and crossings were more widely distributed over a 24-h period during winter months due to longer periods of darkness and confined to a smaller daily time window associated with hours of darkness during summer months. It is likely that EVIs along SR 20 are a combination of increased elk activity during crepuscular and nighttime periods and reduced visibility of drivers during those time periods.

Hotspot lengths were similar in size and did not vary annually in relative position from 2012 to 2019, indicating they were fairly stable and predictable on the landscape. Home range and core use areas were relatively small for sub-herds in the vicinity of SR 20 (Sevigny et al. 2018) and elk spent much of their time in close proximity to the highway. Even with the close proximity to SR 20 and $12 \%$ of total fixes for all collared elk occurring $\leq 200 \mathrm{~m}$ from SR 20, we found that only $2 \%$ of fixes collected were associated with crossings between 2013 and 2019. Further, our 50\% core areas for each sub-herd were located either north or south of SR 20 and did not occur on both sides for any sub-herd. While core areas for collared elk were associated with EVI hotspots, crossing frequencies were lower than we anticipated given the habitat use in proximity to SR 20 .

Hotspots 2 and 3 were adjacent to each other and associated with sub-herds $3,4,5$, and 6 . We chose to separate these hotspots due to a gap between the areas with no EVIs or road crossings between 2012 and 2019. This gap may indicate a spatial boundary between sub-herd ranges because there was no physical barrier preventing elk from accessing and crossing this segment of SR 20. Sub-herds 3 and 4 displayed a small amount of spatial overlap and shared the same segments of SR 20 within their ranges indicating mitigation measures in this area could impact both groups. We did not detect any crossings in sub-herd 6, however that group's HR was adjacent to SR 20. Elk in this sub-herd could be crossing within hotspot 3 and accounting for the EVIs that occurred east of subherd 5's HR. Interestingly, we found 63\% of crossings associated with sub-herd 7 occurred west of associated hotspot 4 in a reach of SR 20 with no reported 
EVIs. This segment of highway is relatively forested and curved, so drivers may reduce their speed due to road conditions and visibility. This reach is also near a posted elk-viewing area, so drivers may be more aware that elk crossings may occur.

\section{Conclusions}

Studies indicate that road-kill can contribute substantially to population trends and changes in vital rates (Braden 2005; Bissonette and Rosa 2012). The EVI sex distribution of $42 \%$ female and $37 \%$ unknown indicates that EVIs along SR 20 could contribute considerably to the survivorship and productivity of the NCEH. Not all elk involved in vehicle collisions die instantly on the highway and therefore recorded EVIs represent a minimum mortality rate associated with road-kill. As female elk sub-herds are likely to continue to use habitat along SR 20, mortality associated with road-kill should be a consideration in harvest modeling.

The Skagit Valley contains high quality forage habitat that is attractive to elk. Previous studies have concluded that elk demonstrate road avoidance based on a variety of factors including traffic, land cover, and road type (Ager et al. 2003; Benkobi et al. 2004; Rowland et al. 2005). In contrast, our elk location data show sedentary female sub-herds acclimated to residing year-round along the SR 20 corridor. Cook et al. (2013) found that elk captured in agricultural pastures had considerably higher body fat levels compared to other coastal elk herds. These results could explain elk preference for floodplain pasture habitat and our observed small HRs for sub-herds along SR 20.

Elk have historically resided in the Skagit Valley and were present even when the population was experiencing declines (Davison 2002; Bender et al. 2006). Because these elk occupy what is believed to be high quality habitat, removal or drastic reduction of elk in the short-term could result in other sub-herds moving into available lowland habitat (Link 2004; Sevigny et al. 2018). For this reason, we should use EVI and crossing data to strategize mitigation planning that will reduce or prevent EVIs. In addition, given that $99 \%$ of EVIs on SR 20 occurred within the 4941 boundary, it would be worthwhile to review harvest and hazing related activities in relation to EVI occurrence.

Identifying EVI hotspots is the first step preceding the development of mitigation measures to prevent elk-vehicle collisions. Specific identification of high-risk areas will result in more effective and successful installations of high cost mitigation efforts such as wildlife crossing structures. We recommend the installation of crossing structures in conjunction with fencing at the 4 identified hotspot locations on SR 20 to effectively reduce the number of EVIs, maintain habitat connectivity, and improve elk survivorship (Bissonette et al. 2012; Gagnon et al. 2015). Planning for these mitigation efforts should include discussions on ways to reduce elk damage to private property along with addressing other local concerns to increase stakeholder support. Exclusionary fencing as stand-alone measure could act as a barrier within HRs, but short segments are effective when used in conjunction with crossing structures (Fairbank 2014; Simpson et al. 2016). Proper placement of crossing structures within known home range areas will help facilitate elk movement across the landscape while reducing EVIs (Bissonette and Adair 2008). Huijser et al. (2009) concluded that the benefits of crossing structures may exceed the associated construction costs for some road segments experiencing concentrated collisions between vehicles and large ungulates.

Other mitigation measures such as speed reduction zones, experimental lighting, and signage could also be effective on certain segments of SR 20. The speed limit within the segment of SR 20 containing hotspots $1-4$ is $55 \mathrm{mph}$. Wang et al. (2010) concluded that road segments with speeds $\geq 50 \mathrm{mph}$ had higher rates of animal-vehicle collisions and $\mathrm{Ng}$ et al. (2008) concluded that driver speed was the prime indicator of deer-vehicle collisions. However, unless speed limits are enforced they are unlikely to significantly lower travel speeds. Most studies involving roadway lighting to reduce wildlife-vehicle collisions are inconclusive (Huijser et al. 2008), however a Transport Canada Report (2003) stated that lighting technology was an effective mitigation measure in high crash locations because it offered drivers a longer reaction time. While artificial lighting can improve driver visibility, it could also deter wildlife activity (Shilling et al. 2016; Ciach and Fröhlich 2019) and cause road crossings to occur in new areas. Lighted signs in the vicinity of known hotspots may be a more 
cost effective approach (Sullivan et al. 2004; Huijser et al. 2008). Along with lighted signs, EVI hotspot areas may benefit from dynamic message signs that indicate the number of animals killed along that road segment (Bond and Jones 2013).

In addition to creating effective mitigation strategies for each hotspot, we recommend improving EVI data collection on SR 20 by requiring sex information for all collision and carcass removal reports, installing traffic counter strips, considering multi-species benefits in mitigation planning, continuing with elk GPS collar monitoring in lowland habitat, and monitoring EVIs in relation to damage-related harvest and hazing activities.

Acknowledgements We thank the co-managers for their monitoring efforts on the North Cascades elk herd. We would like to acknowledge the hard work of the WSDOT maintenance staff who remove and report carcasses and law enforcement staff for recording elk-vehicle collisions. We also thank our partnering landowners in the Skagit Valley for their support. Special thanks to those who reviewed this document.

Open Access This article is licensed under a Creative Commons Attribution 4.0 International License, which permits use, sharing, adaptation, distribution and reproduction in any medium or format, as long as you give appropriate credit to the original author(s) and the source, provide a link to the Creative Commons licence, and indicate if changes were made. The images or other third party material in this article are included in the article's Creative Commons licence, unless indicated otherwise in a credit line to the material. If material is not included in the article's Creative Commons licence and your intended use is not permitted by statutory regulation or exceeds the permitted use, you will need to obtain permission directly from the copyright holder. To view a copy of this licence, visit http://creativecommons.org/licenses/by/4.0/.

\section{References}

Ager A, Johnson BK, Kern JW, Kie JG (2003) Daily and seasonal movements and habitat use by female Rocky Mountain elk and mule deer. J Mamm 84:1076-1088

Baguette M, Van Dyck H (2007) Landscape connectivity and animal behavior: functional grain as a key determinant for dispersal. Landscape Ecol 22:1117-1129

Bartonička T, Andrášik R, Dula M, Sedoník J, Bíl M (2018) Identification of local factors causing clustering of animal-vehicle collisions. J Wildl Manag 82:940-947

Bender LC, Davison MA, Cook JG, Cook RC, Hall PB (2006) Assessing elk population status and potential performance in the Nooksack area, Washington. Northwest Nat 87:98-106
Benkobi L, Rumble MA, Brundige GC, Millspaugh JJ (2004) Refinement of the Arc-Habcap model to predict habitat effectiveness for elk. U.S. Forest Service, Rocky Mountain Research Station, Research paper RMRS-RP-51, Fort Collins

Beringer J, Hansen LP, Wilding W, Fischer J, Sheriff SL (1996) Factors affecting capture myopathy in white-tailed deer. J Wildl Manag 60:373-380

Biggs J, Sherwood S, Michalak S, Hansen L, Bare C (2004) Animal-related vehicle accidents at the Los Alamos National Laboratory, New Mexico. Southwest Nat 49:384-394

Bíl M, Andrášik R, Svoboda T, Sedoník J (2015) The KDE+ software: a tool for effective identification and ranking of animal-vehicle collision hotspots along networks. Landscape Ecol 31:1-7

Bissonette JA, Adair W (2008) Restoring habitat permeability to roaded landscapes with isometrically-scaled wildlife crossings. Biol Conserv 141:482-488

Bissonette JA, Rosa S (2012) An evaluation of a mitigation strategy for deer-vehicle collisions. Wildl Biol 18:414-423

Bond ARF, Jones DN (2013) Wildlife warning signs: Public assessment of components, placement and designs to optimise driver response. Animals 3:1142-1161

Braden AW (2005) Evaluation of the effects of a highway improvement project on Key deer. Master of Science Thesis, Texas A\&M University

Brady P, Richardson JL (2017) Road ecology: shifting gears toward evolutionary perspectives. Front Ecol Environ 15:91-98

Bruggeman JE, Garrott RA, White PJ, Watson FGR, Wallen R (2007) Covariates affecting spatial variability in bison travel behavior in Yellowstone National Park. Ecol Appl 17:1411-1423

Bunnefeld N, Borger L, Van Moorter B, Rolandsen C, Dettki H, Solberg EJ, Ericsson G (2011) A model-driven approach to quantify migration patterns: individual regional and yearly differences. J Anim Ecol 80:466-476

Ciach M, Fröhlich A (2019) Ungulates in the city: light pollution and open habitats predict the probability of roe deer occurring in an urban environment. Urban Ecosyst. https://doi.org/10.1007/s11252-019-00840-2.Accessed8J uly 2020

Clover MR (1954) A portable deer trap and catch-net. CA Fish Game 40:367-373

Conover MR, Pitt WC, Kessler KK, DuBow TJ, Sanborn WA (1995) Review of human injuries, illnesses, and economic losses caused by wildlife in the United States. Wildl Soc B 23:407-414

Cook RC, Cook JG, Vales DJ, Johnson BK, McCorquodale SM, Shipley LA, Riggs RA, Irwin LL, Murphie SJ, Murphie BL, Schoenecker KA, Geyer F, Hall PB, Spencer RD, Immell DA, Jackson DH, Tiller BL, Miller PJ, Schmitz L (2013) Regional and seasonal patterns of nutritional condition and reproduction in elk. Wildl Monogr 184:1-44

Craighead JJ, Craighead FC, Ruff RL, O'Gara BW (1973) Home ranges and activity patterns of non-migratory elk of the Madison drainage herd as determined by biotelemetry. Wildl Monogr 33:1-50 
Danks ZD, Porter WF (2010) Temporal, spatial, and landscape habitat characteristics of moose-vehicle collisions in western Maine. J Wildl Manag 74:1229-1241

Davison, MA (2002) Washington State elk herd plan: North Cascade elk herd. Washington Department of Fish and Wildlife Report. https://digitalarchives.wa.gov/do/7DB78 B50B1BBA8DEE87D8EB87442D9F3.pdf. Accessed 1 July 2020

Dodd NL, Gagnon JW, Boe S (2006) Characteristics of elkvehicle collisions and comparison to GPS-determined highway crossing patterns. In: Irwin CL, Garrett $\mathrm{P}$, McDermott KP (eds) Proceedings of the International Conference on Ecology and Transportation, Center for Transportation and the Environment, North Carolina State University, Raleigh, pp 461-477

Dodd NL, Gagnon JW, Boe S, Scheweinsburg RE (2007) Assessment of elk highway permeability by using Global Positioning System telemetry. J Wildl Manag 71:1107-1117

Dyer SJ, O’Neill JP, Wasel SM, Boutin S (2002) Quantifying barrier effects of roads and seismic lines on movements of female woodland caribou in northeastern Alberta. Can J Zool 80:839-845

Fahrig L, Rytwinski T (2009) Effects of roads on animal abundance: an empirical review and synthesis. Ecol Soc 14:1-20

Fairbank ER (2014) Use and effectiveness of wildlife crossing structures with short sections of wildlife fencing. Master of Science Thesis, University of Montana

Favilli F, Bíl M, Sedoník J, Andrášik R, Kasal P, Agreiter A, Streifeneder T (2018) Application of KDE+ software to identify collective risk hotspots of ungulate-vehicle collisions in South Tyrol, northern Italy. Eur J Wildl Res 64:1-12

Forman RTT, Sterling D, Bissonette JA, Clevenger AP, Cutshall CD, Dale VH, Fahrig L, France R, Goldman CR, Heanue K, Jones JA, Swanson FJ, Turrentine T, Winter TC (2003) Road ecology: science and solutions. Island Press, Washington DC

Franklin JF, Dyrness CT (1988) Natural vegetation of Oregon and Washington. Oregon State University Press, Corvallis

Gagnon JW, Theimer TC, Dodd NL, Boe S, Schweinsburg RE (2007) Traffic volume alters elk distribution and highway crossings in Arizona. J Wildl Manag 71:2318-2323

Gagnon JW, Loberger CD, Sprague SC, Ogren KS, Boe SL, Schweinsburg RE (2015) Cost-effective approach to reducing collisions with elk by fencing between existing highway structures. Hum Wildl Interact 9:248-264

Garrah E, Danby RK, Eberhardt E, Cunnington GM, Mitchell S (2015) Hot spots and hot times: wildlife road mortality in a regional conservation corridor. Environ Manag. https://doi.org/10.1007/s00267-015-0566-1

Gunson KE, Clevenger AP (2003) Large animal-vehicle collisions in the central Canadian Rocky Mountains: patterns and characteristics. In: Irwin CL, Garrett P, McDermott KP (eds) Proceedings of the International Conference on Ecology and Transportation, North Carolina Center for Transportation and the Environment, North Carolina State University, Raleigh, pp 355-366

Hemson G, Johnson P, South A, Kenward R, Ripley R, MacDonald D (2005) Are kernels the mustard? Data from global positioning system (GPS) collars suggests problems for kernel home-range analyses with least-squares cross-validation. J Anim Ecol 74:455-463

Homer C, Dewitz J, Jin S, Xian G, Costello C, Danielson P, Gass L, Michelle F, Wickham J, Stehman S, Auch R, Riitters K (2020) Conterminous United States land cover change patterns 2001-2016 from the 2016 National Land Cover Database. J Photogramm Remote Sens 162:184-199

Huijser MP, McGowen P, Fuller J, Hardy A, Kociolek A, Clevenger AP, Smith D, Ament R (2008) Wildlife-vehicle collision reduction study: report to Congress. Technical Report, U.S. Department of Transportation, Federal Highway Administration, pp 1-251

Huijser MP, Duffield JW, Clevenger AP, Ament RJ, McGowen PT (2009) Cost-benefit analyses of mitigation measures aimed at reducing collisions with large ungulates in the United States and Canada: a decision support tool. Ecol Soc 14: http://www.ecologyandsociety.org/vol14/iss2/ art15/. Accessed 30 June 2020

Johnson CJ, Parker KL, Heard DC, Gillengham MP (2002) A multiscale behavioral approach to understanding the movements of woodland caribou. Ecol Appl 12:1840-1860

Jones MC, Marron JS, Sheather SJ (1996) A brief survey of bandwidth selection for Density Estimation. J Am Stat Assoc 91:401-407

Kernohan BJ, Gitzen RA, Millspaugh JJ (2001) Analysis of animal space use and movements. In: Marzluff JM (ed) Radio tracking and animal populations. Academic Press, San Diego, pp 125-166

Kociolek A, Craighead L, Brock B, Craighead A (2016) Evaluating wildlife mortality hotspots, habitat connectivity, and potential mitigation in the Madison Valley. Western Transportation Institute Report, FHWA/MT-16-016/8217001, Montana State University, Bozeman

Link R (2004) Living with wildlife in the Pacific Northwest. University of Washington Press, WA

McCullough DR (1975) Modification of the clover deer trap. CA Fish Game 61:242-244

Morelle K, Lehaire F, Lejeune P (2013) Spatio-temporal patterns of wildlife-vehicle collisions in a region with a highdensity road network. Nat Conserv 5:53-73

Murie A (1951) The elk of North America. Stackpole Company, Harrisburg

Myers WL, Chang WY, Germaine SS, Vander Haegen WM, Owens TE (2008) An analysis of deer and elk-vehicle collision sites along state highways in Washington State. Washington Department of Fish and Wildlife Technical Report. https://www.wsdot.wa.gov/research/reports/fullr eports/701.1.pdf. Accessed 30 June 2020

Neumann W, Ericsson G, Dettki H, Bunnefeld N, Keuler NS, Helmers DP, Radeloff VC (2012) Difference in spatiotemporal patterns of wildlife road-crossings and wildlife-vehicle collisions. Biol Conserv 145:70-78

Ng JW, Nielsen C, St C, Clair C (2008) Landscape and traffic factors influencing deer-vehicle collisions in an urban environment. Hum Wildl Conflicts 2:34-47

Powell RA, Mitchell MS (2012) What is home range? J Mammal 93:948-958 
Prokopenko C, Boyce MS, Avgar T (2017) Characterizing wildlife behavioral responses to roads using integrated step selection analysis. J Appl Ecol 54:470-479

Puglisi MJ, Lindzey JS, Bellis ED (1974) Factors associated with highway mortality of white-tailed deer. J Wildl Manag 38:799-807

Ramp D, Caldwell J, Edwards KA, Warton D, Croft DB (2005) Modelling of wildlife fatality hotspots along the Snowy Mountain Highway in New South Wales, Australia. Biol Conserv 126:474-490

Romin LA, Bissonette JA (1996) Deer-vehicle collisions: status of state monitoring activities and mitigation efforts. Wildl Soc B 24:276-283

Roper LA, Schmidt RL, Gill RB (1971) Techniques of trapping and handling mule deer in northern Colorado with notes on using automatic data processing for data analysis. Proc Western Assoc Game Fish Comm 51:471-477

Rowland MM, Wisdom MJ, Johnson BK, Penninger MA (2005) Effects of roads on elk: Implications for management in forested ecosystems. Transactions of the 69th North American Wildlife and Natural Resources Conference 69:491-508

Seaman DE, Powell RA (1996) An evaluation of the accuracy of kernel density estimators for home range analyses. Ecology 77:2075-2085

Sevigny JM, Sevigny M, George-Wirtz E, Summers A (2018) Spatial distribution, site fidelity, and home range overlap in the North Cascades elk herd: implications for management. Northwest Sci 92:251-266

Shilling F, Collins A, Louderback-Valenzuela A, Farman P, Guarnieri M, Longcore T, Banet B, Knapp H (2016) Wildlfe-crossing mitigation effectiveness with traffic noise and light. National Center for Sustainable Transportation. https://escholarship.org/content/qt8893d8zw/qt8893d8zw. pdf?t=q2arfw. Accessed 8 July 2020

Sikes RS, The Animal Care and Use Committee of the American Society of Mammalogists (2016) Guidelines of the American Society of Mammalogists for the use of wild mammals in research and education. J Mammal 97:663-688

Silverman BW (1986) Density estimation for statistics and data analysis. Monographs on Statistics and Applied Probability, London, UK. https://ned.ipac.caltech.edu/level5/ March02/Silverman/paper.pdf. Accessed 1 July 2020

Simpson NO, Stewart KM, Schroeder C, Cox M, Huebner K, Wasley T (2016) Overpasses and underpasses: effectiveness of crossing structures for migratory ungulates. $\mathrm{J}$ Wildl Manag 80:1370-1378
Snow NP, Williams DM, Porter WF (2014) A landscape-based approach for delineating hotspots of wildlife-vehicle collisions. Landsc Ecol 29:817-829

Sullivan TL, Williams AF, Messmer TA, Hellinga LA, Kyrychenko SY (2004) Effectiveness of temporary warning signs in reducing deer-vehicle collisions during mule deer migrations. Wildl Soc B 32:907-915

Thompson MJ, Henderson RE, Lemke TO, Sterling BA (1989) Evaluation of a collapsible clover trap for elk. Wildl Soc B 17:287-290

Transport Canada (2003) Overview of technologies aimed at reducing and preventing large animal strikes. K1A 0N5. https://www.wildlifecollisions.ca/docs/e063e9492a 82fbb7.pdf. Accessed 1 July 2020

Trombulak SC, Frissell CA (2000) Review of ecological effects of roads on terrestrial and aquatic communities. Conserv Biol 14:18-30

Van Dyke F (2007) Colonization of non-traditional range in dispersing elk, Cervus elaphus nelsoni, populations. Can Field Nat 121:133-141

Waller JS, Servheen C (2005) Effects of transportation infrastructure on grizzly bears in northwestern Montana. J Wildl Manag 69:985-1000

Wand MP, Jones MC (1994) Kernel smoothing. Chapman and Hall, London

Wang Y, Lao Y, Wu Y, Corey J (2010) Identifying high risk locations of animal-vehicle collisions on Washington State highways. Washington State Transportation Center Report. https://media.digitalarchives.wa.gov/do/52268 DC32CD118BED96FEE015AD4BEE3.pdf. Accessed 1 July 2020

Washington Department of Fish and Wildlife (2012-2019) Status and Trends Reports. https://wdfw.wa.gov/publications. Accessed 30 June 2020

Washington Department of Fish and Wildlife (2015) Washington's state wildlife action plan: 2015 update. Washington Department of Fish and Wildlife. https://wdfw.wa.gov/ sites/default/files/publications/01742/wdfw01742.pdf. Accessed 30 June 2020

Publisher's Note Springer Nature remains neutral with regard to jurisdictional claims in published maps and institutional affiliations. 